\title{
Shock Tube Studies of Ethanol Preignition
}

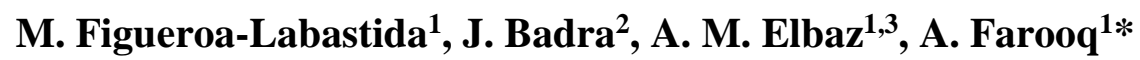 \\ ${ }^{1}$ King Abdullah University of Science and Technology, Clean Combustion Research Center, \\ Physical Sciences and Engineering Division, Thuwal 23955-6900, Saudi Arabia \\ ${ }^{2}$ Fuel Technology Division, R\&DC, Saudi Aramco, Dhahran, 31311, Saudi Arabia \\ ${ }^{3}$ Faculty of Engineering -Mattaria, Helwan University, Cairo Egypt.
}

Corresponding author email: aamir.farooq@kaust.edu.sa

Full-length article 


\begin{abstract}
Understanding premature ignition or preignition is of great importance as this phenomenon influences the design and operation of internal combustion engines. Preignition leading to super-knock restricts the efficiency of downsized boosted engines. To gain a fundamental understanding of preignition and how it affects an otherwise homogeneous ignition process, a shock tube may be used to decipher the influence of fuel chemical structure, temperature, pressure, equivalence ratio and bath gas on preignition. In a previous work by Javed et al. [1], ignition delay time measurements of nheptane showed significantly expedited reactivity compared to well-validated chemical kinetic models in the intermediate-temperature regime. In the current work, ethanol is chosen as a representative fuel that, unlike n-heptane, does not exhibit negative temperature coefficient (NTC) behaviour. Reactive mixtures containing $2.9 \%$ and $5 \%$ of ethanol at equivalence ratios of 0.5 and 1 were used for the measurement of ignition delay times behind reflected shock waves at 2 and 4 bar. Effect of bath gas was studied with mixtures containing either Ar or $\mathrm{N}_{2}$. In addition to conventional side-wall pressure and $\mathrm{OH}^{*}$ measurements, a high-speed imaging setup was utilized to visualize the shock tube crosssection through a transparent quartz end-wall. The results suggest that preignition events are more likely to happen in mixtures containing higher ethanol concentration and that preignition energy release is more pronounced at lower temperatures. High-speed imaging shows that low-temperature ignition process is usually initiated from an individual hot spot that grows gradually, while hightemperatures ignition starts from many spots simultaneously which consume the reactive mixture almost homogeneously.
\end{abstract}

Keywords: Preignition; Ethanol; Shock tube; High-speed imaging; Ignition delay times. 


\section{Introduction}

Preignition, which is an ignition event before it is expected and generally where it is not expected, is a type of abnormal combustion that has been observed since the 1920s [2] in systems such as aircraft [3] and automotive internal combustion (IC) engines [4]. As these engineering systems have evolved with time, the factors that lead to preignition back then could be different to those observed nowadays [5]. Generally, preignition hypotheses revolve around the existence of hot surfaces [6] or hot particles $[7,8,9]$ that can be the source of end-gas ignition during an engine cycle. The importance of understanding preignition lays on the negative effects that it can cause on engines, such as highpressure events identified as knock [10] or the more dramatic superknock [11], and the limitations it puts on designing modern downsized engines.

Shock tubes provide a nearly ideal chemical reactor [12] to study ignition phenomena as a function of temperature, pressure and fuel/oxidizer mixture composition. Conscious of the different nature of physics happening in a shock tube and in an engine, one has to be careful in directly extending the conclusions drawn from shock tube experiments to engines and other devices. Nevertheless, a shock tube provides a well-controlled and simple environment to study preignition than trying to decouple it from many other phenomena in an engine. Previously, Uygun et al. [13] observed appreciable preignition pressure rise during the ignition of 2-methylfuran in a shock tube. They used schlieren imaging to show that the main ignition event was preceded by deflagrative flame kernels. Javed et al. [1] reported expedited shock tube ignition delay measurements of $n$-heptane in the intermediate temperature (or NTC) region. Computational fluid dynamic (CFD) simulations of a randomly located hot spot in the test section showed that energy release from the hot spot can expedite ignition delay times, in agreement with their experimental observations. Troutman et al. [14] analyzed the inhomogeneous combustion of $n$-heptane mixtures and related their findings to optical window recessions and cleanliness in the shock tube facility. Recently, Ninnemann et al. [15] observed preignition for high-concentration hydrogen/oxygen mixtures, identifying mild combustion events starting with weak flame kernels. 
Preignition phenomenon has also been studied in rapid compression machines (RCMs). Walton et al. [16] used high-speed imaging in their rapid compression facility and observed localized reaction front propagation for fuel concentrations above a critical value in syngas and iso-octane mixtures. Wang et al. [17] also utilized high-speed imaging in an RCM to describe the superknock process for iso-octane, where they identified deflagration, detonation and posterior pressure oscillations.

High-speed imaging is a non-intrusive technique that can give a good physical insight of the processes leading to preignition events and the way this phenomenon evolves in the system. High-speed analyses have been performed in engine cycles [18], rapid compression machines [16, 17, 19], flames [20] and spray characterization [21]. High-speed $\mathrm{OH}^{*}$ chemiluminescence may be related to the rate of heat release of the observed phenomenon [22]. Some imaging experiments have recently been performed in shock tubes for the investigation of combustion homogeneity with various fuels, such as n-heptane, hydrogen and syngas [14-15, 23-27].

In the current work, ethanol is chosen as a representative non-NTC fuel which is thought to be quite prone to preignition $[28,29]$ due to its relatively small laminar flame thickness. The combustion chemistry of ethanol has been extensively studied previously with experiments and modelling [30], and the literature kinetic models are, generally, quite reliable. Here, measured ignition delay times of ethanol are compared with chemical kinetic simulations to illustrate the effects of preignition on the autoignition characteristics of ethanol. Additionally, high-speed $\mathrm{OH}^{*}$ chemiluminescence setup is used to record two-dimensional images of the reaction sequence through the shock tube end-wall. The imaging results are used to understand the processes and thermodynamic conditions that dictate ethanol preignition. 


\section{Experimental Details}

\subsection{Ignition Delay Time Setup}

Ignition delay times of various mixtures of ethanol/oxygen/argon and ethanol/oxygen/nitrogen were measured behind reflected shock waves using the low-pressure shock tube (LPST) facility at King Abdullah University of Science and Technology (KAUST). The driver and driven section of this facility are each $9.1 \mathrm{~m}$ long, separated by a polycarbonate diaphragm, with an inner diameter of 14.2 $\mathrm{cm}$. The driver section is modular with four sub-sections, and the number of sections used depends on the desired test time of the experiment. To study ethanol ignition at low temperatures, long test times were achieved by using the full length of the driver section and employing driver gas tailoring [31]. Incident shock speed was measured using a series of five piezoelectric PCB pressure transducers over the last $1.5 \mathrm{~m}$ of the shock tube. Reflected shock temperatures and pressures were determined from the measured incident shock speed and normal shock relations [32]. A Kistler 603B piezoelectric pressure transducer, located at $2 \mathrm{~cm}$ from the driven section endwall, was used to measure pressure timehistories. A line-of-sight $\mathrm{OH}^{*}$ emission diagnostic was implemented using Thorlabs PDA36A detector at the sidewall of the shock tube. Ignition delay times reported here were deduced from pressure traces by extrapolating a line tangent to the point of maximum rate-of-change of pressure. Gaseous mixtures were prepared using a magnetically-stirred mixing vessel and a well-furnished mixing manifold. The shock tube and mixing tank can be heated to temperatures up to $100{ }^{0} \mathrm{C}$ with a heating jacket [1]. Ethanol (> 99.8\%) from Sigma-Aldrich, oxygen, nitrogen and argon gas (99.999\%) from Air Liquide were used.

\subsection{High-Speed Imaging Setup}

High-speed $\mathrm{OH}^{*}$ chemiluminescence imaging experiments were performed using the setup shown in Fig. 1. The objective of the imaging experiments was to visually explore the conditions that showed some sign of preignition occurrence during the ignition delay measurements. A high-speed camera (LaVision High Speed Star 6), coupled to a high-speed UV Intensifier (LaVision IRO) and a VZ-UV focusing objective, was operated at $10 \mathrm{kHz}$ to capture shock tube cross-sectional images. A $100 \mathrm{~mm} \mathrm{x}$ 
$100 \mathrm{~mm}$ UV-enhanced mirror was used to deflect the emission at right angle. A $310 \mathrm{~nm}$ bandpass filter with a FWHM of $10 \mathrm{~nm}$ was placed on the camera lens. An IRO controller was used to synchronize the imaging system with the reflected shock wave. For the IRO system, a gate opening time of 3000 ns was used, and the gain was varied from 57 to 65 depending on the intensity or counts registered in the experiments to avoid signal saturation and to achieve adequate signal level.

The transparent endwall consisted of a fused silica disk with $16.4 \mathrm{~cm}$ diameter and $45 \mathrm{~mm}$ thickness. Special rubber gaskets were needed to minimize the strain due to the contact of the glass and steel and to ensure good vacuum conditions inside the shock tube. The location and orientation of the UVenhanced mirror was optimized to get complete image of the region of interest. Optimal location and focus point of the imaging optics were found using standard grids and optical references. The trigger signal used to start the recordings was a TTL signal obtained from a Stanford Research Systems DG535 delay generator connected to the pressure transducer closest to the shock tube endwall.

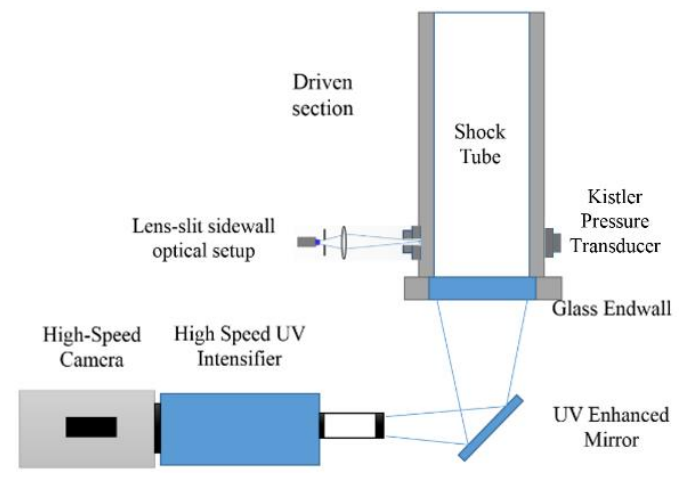

Fig. 1. High-speed $\mathrm{OH}^{*}$ imaging setup through the quartz (glass) endwall. Sidewall $\mathrm{OH}^{*}$ emission and pressure diagnostics at $2 \mathrm{~cm}$ from endwall are also shown.

\section{Results and Discussion}

\subsection{Ignition Delay Time Measurements}

Ignition delay times (IDTs) were initially measured for stoichiometric ethanol/oxygen/argon mixtures containing $2.9 \%$ of ethanol at a pressure of 2 bar. This specific mixture and conditions were chosen to be compared with high-temperature $(\mathrm{T}>1100 \mathrm{~K})$ ignition delay measurements by Noorani et al. [33]. 
The two data sets agreed very well, as depicted in Fig. 2. Our measurements were extended to lower temperatures $(\sim 900 \mathrm{~K})$ and modeled using the chemical kinetic model of Metcalfe et al. [34]. Simulations were carried out using Chemkin-Pro in two ways: (1) constant-UV assumption, (2) constant $\mathrm{U}$ and a volume profile generated with $\mathrm{dP} / \mathrm{dt}$ of $2 \% / \mathrm{ms}$. This value of $\mathrm{dP} / \mathrm{dt}$ represented an average post-reflected-shock pressure rise measured in our experiments. Experimental IDTs at low temperatures were in very good agreement with the simulated ignition delays employing $2 \% / \mathrm{ms} \mathrm{dP} / \mathrm{dt}$. Additionally, IDTs of $2.9 \%$ ethanol mixture were measured at lean $(\phi=0.5)$ conditions over $850-$ $1200 \mathrm{~K}$ and 2 bar. These data also agreed with the $\mathrm{dP} / \mathrm{dt}$ imposed model predictions (right panel of Fig. 2).
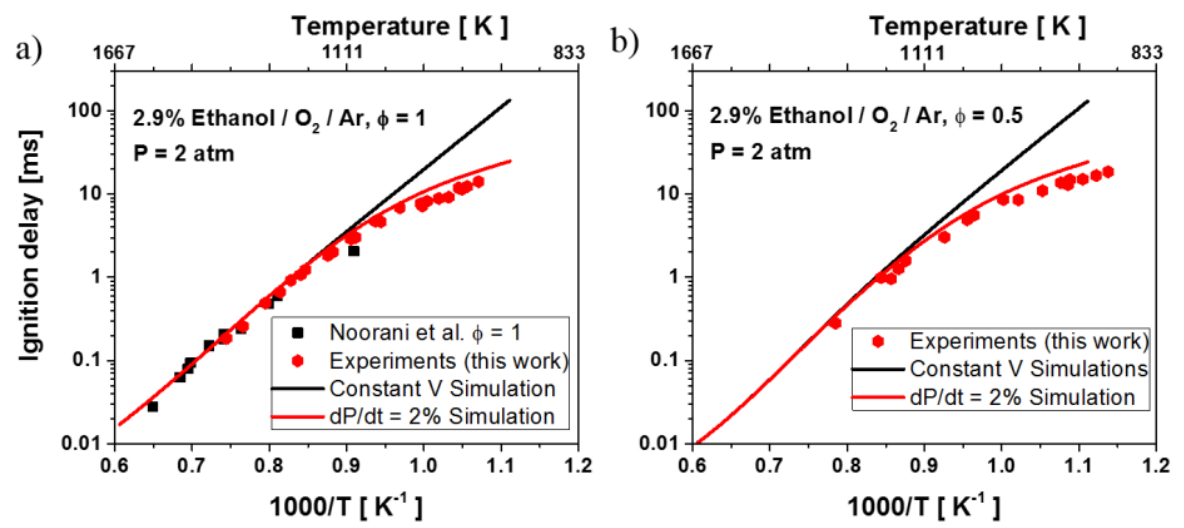

Fig. 2. Ignition delay times of mixtures with a) $2.9 \%$ ethanol/ $8.7 \% \mathrm{O}_{2} / \mathrm{Ar}$ and (b) $2.9 \%$ ethanol/ $17.4 \%$ $\mathrm{O}_{2} / \mathrm{Ar}$. Nominal reflected shock pressure is $2 \mathrm{~atm}$. Simulations performed in ChemKin using Metcalfe et al.

[34] chemical kinetic mechanism.

Ignition delay experiments were then carried out for mixtures containing a higher fraction (fixed at $5 \%$ ) of ethanol at lean and stoichiometric conditions and pressures of 2 and 4 bar; these data are presented in Fig. 3. The measured IDTs agreed with model predictions for $\phi=1$ at both pressures. However, lean mixtures, which contained more oxygen in the mixture, exhibited significant deviation from the predicted values at low temperatures despite the $\mathrm{dP} / \mathrm{dt}$ consideration. The deviation between measured and calculated low-temperature IDTs ranged between a factor of 2 to 4 . These experiments were carried out with various degrees and combinations of shock tube cleaning processes (e.g., turbopumped to $10^{-5}$ Torr, rough-pumped to $10^{-2}$ Torr, scrubbed with acetone, diaphragm pieces from 
previous runs removed / left, etc.). No systematic effect of the cleaning procedure was observed on the results. The measured ignition delays were thus quite repeatable and pointed to some sort of physical/chemical process resulting in significantly faster IDTs. Measurements affected by preignition are shown as open symbols. IDTs were considered to be preignition affected when the pressure trace exhibited a gradual increase of at least $20 \%$ of the plateau value before the main ignition (exponential rise in pressure).
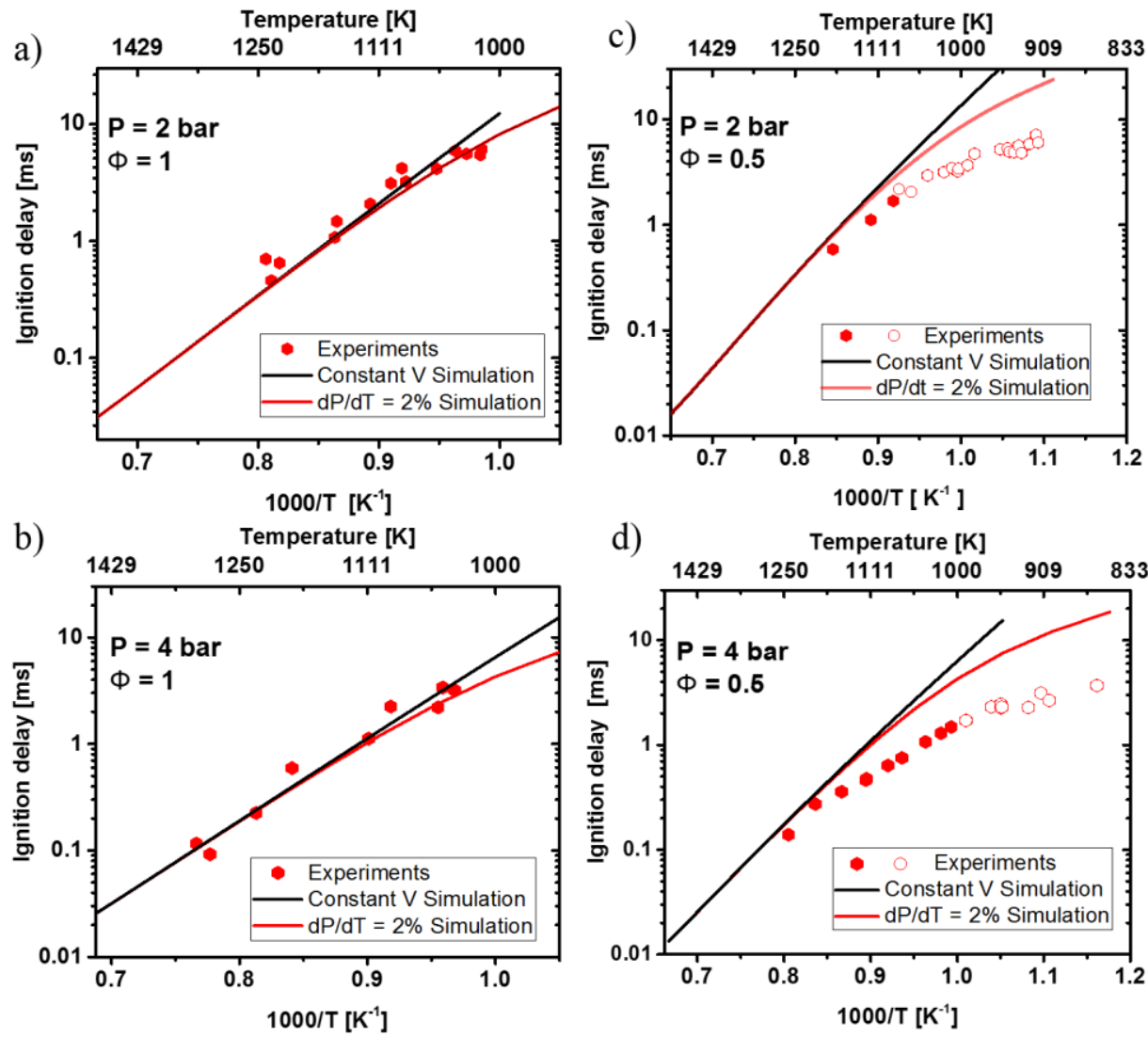

Fig. 3. Ignition delay times of $5 \%$ ethanol $/ 15 \% \mathrm{O}_{2} / \mathrm{Ar}, \Phi=1$ at a) 2 bar and b) 4 bar, and $5 \%$ ethanol $130 \% \mathrm{O}_{2} / \mathrm{Ar}, \Phi=0.5$ at c) 2 bar and d) 4 bar. Open circles denote preignition affected measurements.

Simulations performed in ChemKin using Metcalfe et al. [34] chemical kinetic mechanism.

A few representative measured pressure traces for the $5 \%$ ethanol and $\Phi=0.5$ mixture are shown in Fig. 4. At high temperatures, a strong ignition process with a rapid pressure increase was observed which is indicative of homogenous ignition. At lower temperatures (1042 and $992 \mathrm{~K}$ ), a gradual pressure increase (or gradual heat release), labelled as preignition, was observed before the main ignition event. These pressure traces suggested the existence of a preignition flame kernel, in 
agreement with the hypothesis of Javed et al. [1]. Pressure traces at both 2 and 4 bar showed quite similar behavior across the temperature range.

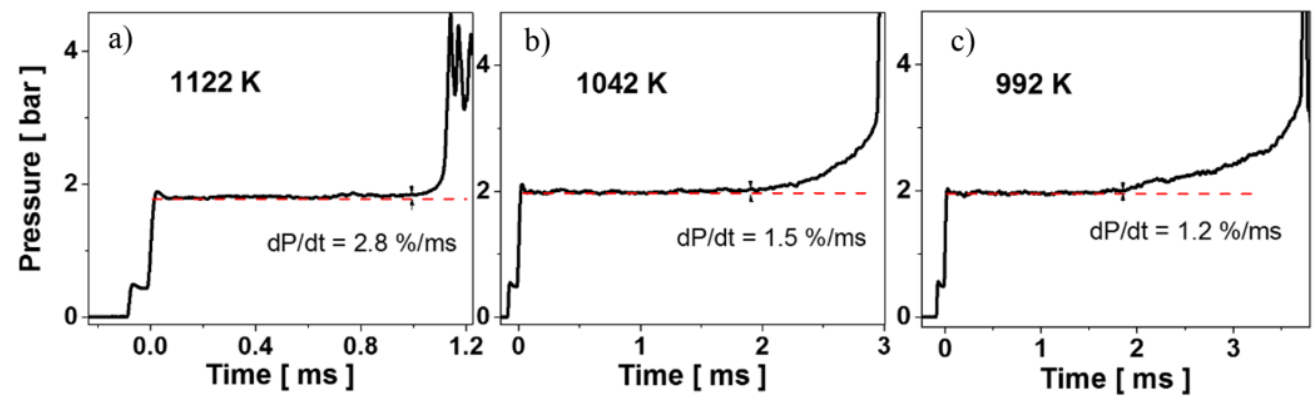

Fig. 4. Pressure time-histories for $5 \%$ ethanol $/ 30 \% \mathrm{O}_{2} / \mathrm{Ar}$ mixture at $\Phi=0.5$ and $\mathrm{P}=2$ bar.

Additional experiments were performed to evaluate the impact of the bath gas used on the nonhomogeneous ignition observed. For this, argon was replaced with nitrogen in the mixtures containing $5 \%$ ethanol at equivalence ratios of 0.5 and 1 at 2 bar. Measured ignition delay times are shown in Fig. 5. Similar to the argon containing mixtures, ignition delay times agreed with $\mathrm{dP} / \mathrm{dt}$ simulations for the stoichiometric case but the lean mixture exhibited expedited ignition delays. A comparison between Ar and $\mathrm{N}_{2}$ containing experiments at $\Phi=0.5$ shows that argon mixtures are slightly more prone to preignition than the $\mathrm{N}_{2}$ mixtures. Shock bifurcation is sometimes postulated as a potential cause of inhomogeneous ignition in shock tube experiments where diatomic gas, such as nitrogen, enhances bifurcation [35]. Therefore, our results suggest that boundary layer separation and/or shock bifurcation are not the main source of preignition events in the experiments reported herein. Non-reactive experiments, using nitrogen as a substitute for oxygen, support this notion by not showing any marked pressure increase during the test time. It may be pointed out that chemical kinetic simulations were carried out with both argon and nitrogen bath gas, and the homogeneous ignition delay times were indistinguishable for the two bath gases. 

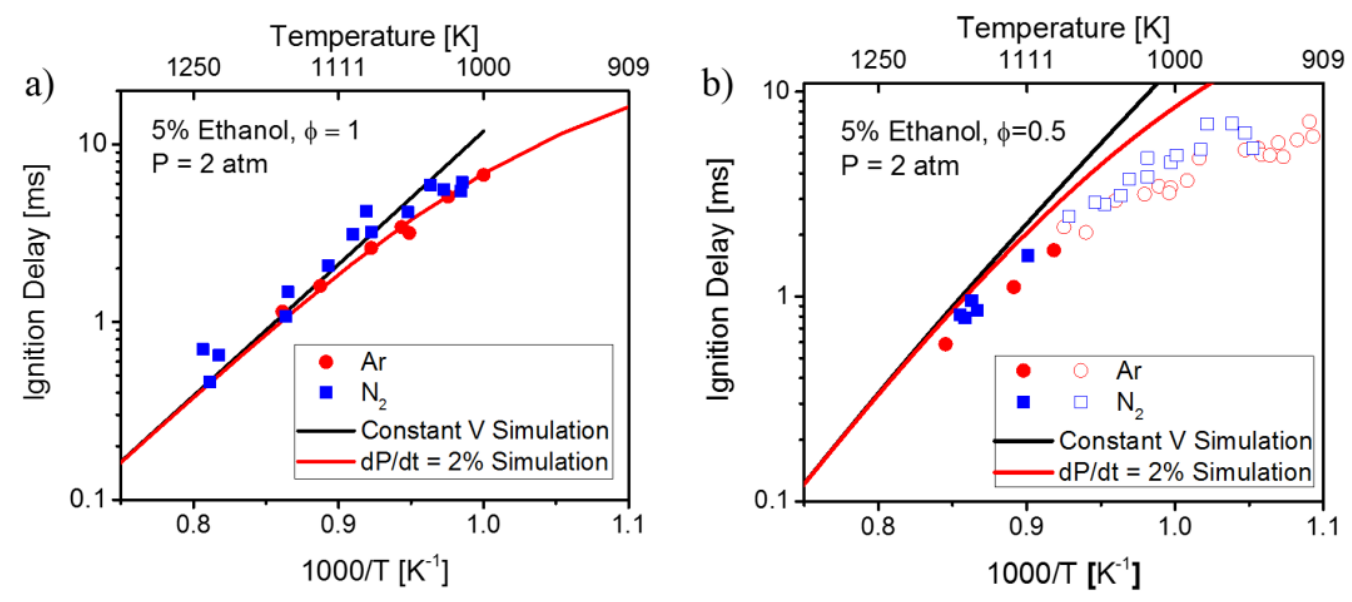

Fig. 5. Ignition delay times of 5\% ethanol / $\mathrm{O}_{2} / \mathrm{N}_{2}$ mixtures and comparison between $\mathrm{Ar}$ and $\mathrm{N}_{2}$ containing mixtures. Open symbols denote preignition affected measurements.

We would like to point out that ignition delay experiments characterized by significant preignition heat release cannot be described or modeled by simply employing a facility-dependent $\mathrm{dP} / \mathrm{dt}$ correction. Such ignition cases represent localized ignition processes, as described later with $\mathrm{OH}^{*}$ imaging experiments, and should not be used as such for validating chemical kinetic models. To this end, we would like to differ with the conclusions of the recent study of Ninnemann et al. [15] who argued that the low-temperature hydrogen ignition cases affected by preignition were adequately modeled by simulations with $\mathrm{dP} / \mathrm{dt}$ correction. In fact, one can observe clearly in Fig. 8 and Fig. 11 of their paper that the preignition cases are faster than the $\mathrm{dP} / \mathrm{dt}$ model predictions.

Analysis of the ignition delay data obtained for ethanol mixtures showed that the governing factors affecting preignition behavior were the fuel concentration and equivalence ratio. Table 1 is a summary of these results, where the main observation is that preignition events were only observed when the oxygen concentration in the mixture was $30 \%$. 
Table 1. Preignition observation at low temperatures for various experimental conditions

\begin{tabular}{|c|c|c|c|c|c|c|}
\hline \multirow[t]{2}{*}{ Pressure } & \multirow[t]{2}{*}{$\Phi$} & \multicolumn{4}{|c|}{ Composition (mole \%) } & \multirow[t]{2}{*}{ Pre-ignition } \\
\hline & & Ethanol & $\mathrm{O}_{2}$ & $\mathrm{Ar}$ & $\mathrm{N}_{2}$ & \\
\hline 2 & 0.5 & 2.9 & 8.8 & 88.3 & 0 & No \\
\hline 2 & 1 & 2.9 & 17.4 & 79.7 & 0 & No \\
\hline 2 & 1 & 5 & 15 & 80 & 0 & No \\
\hline 4 & 1 & 5 & 15 & 80 & 0 & No \\
\hline 2 & 1 & 5 & 15 & 0 & 80 & No \\
\hline 2 & 0.5 & 5 & 30 & 65 & 0 & Yes \\
\hline 4 & 0.5 & 5 & 30 & 65 & 0 & Yes \\
\hline 2 & 0.5 & 5 & 30 & 0 & 65 & Yes \\
\hline
\end{tabular}




\subsection{High-Speed Imaging Experiments}

To further investigate the preignition heat release and inhomogeneous ignition, high-speed $\mathrm{OH}^{*}$ chemiluminescence imaging was performed for the $5 \%$ ethanol / 30\% oxygen / argon $(\Phi=0.5)$ mixture at pressures near 2 bar. These imaging experiments were carried out at both high- and low-temperature conditions.

At relatively high temperatures $(\sim 1200 \mathrm{~K})$, emission was observed in the $\mathrm{OH}^{*}$ images when the measured pressure trace began to grow abruptly. Around $0.1 \mathrm{~ms}$ after the initial emission observation, flame kernels seemed to populate the shock tube cross-section in a fast and homogeneous manner, burning the complete mixture exponentially. This leads to strong ignition which is identified as a steep and pronounced rise in the pressure trace (Fig. 4a, 1122 K). For such fast events, the frame acquisition rate of the imaging setup plays an important role, since some information may be lost or skipped if the time between successive frames is relatively long. A representative imaging sequence is shown in Fig. 6 for a high-temperature case at $1183 \mathrm{~K}$. Normalized camera intensity, shown in Fig. 6, agrees quite well with the pressure trace. Similar chain of events was observed for other experiments in the $1100-1200 \mathrm{~K}$ range, where emission starts at random places, followed quickly by an almost uniform strong emission which occupies the entire viewing window. This is the expected combustion mechanism for a shock tube where the temperature and pressure after the reflected shock are uniform, resulting in nearly homogeneous ignition. 


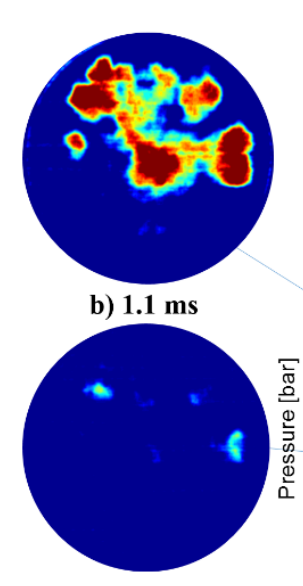

a) $1 \mathrm{~ms}$
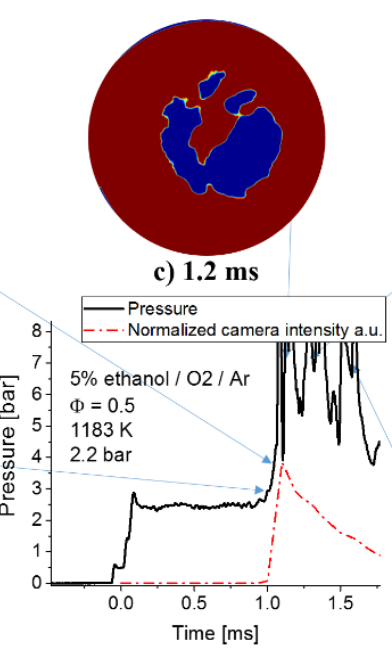

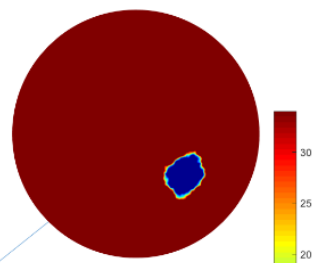

d) $1.3 \mathrm{~ms}$

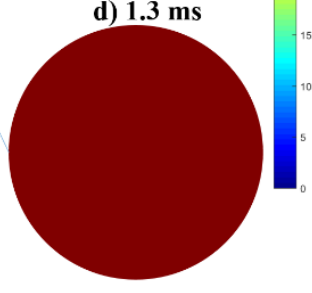

e) $1.6 \mathrm{~ms}$

Fig. 6. Ethanol combustion at $1183 \mathrm{~K}$ and 2.2 bar. $\mathrm{OH}^{*}$ images at various times are shown. At such high temperatures, many spots appear simultaneously and consume the mixture abruptly.

Localized / non-homogeneous ignition was observed at lower temperatures in the high-speed imaging experiments. Figure 7 shows a representative case at $898 \mathrm{~K}$ and 1.7 bar, where it can be seen that at early stages, when the pressure trace exhibits slight pressure increase due to heat release, the $\mathrm{OH}^{*}$ chemiluminescence images depict two bright spots at the lower left side of the shock tube cross-section. The two spots combine quickly and keep growing as a single kernel until the main ignition event occurs at about $5.9 \mathrm{~ms}$. It should be noted that the pressure rise over $\sim 4-$ $6 \mathrm{~ms}$ cannot be described by the usual non-idealities of the shock tube and has a direct correspondence with the growth and development of the emitting kernel. Figure 7 also shows normalized camera intensity which provides a very similar shape to the heat release trend depicted by the pressure trace. 


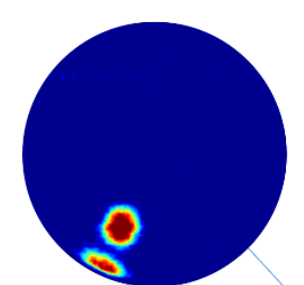

b) $3.8 \mathrm{~ms}$

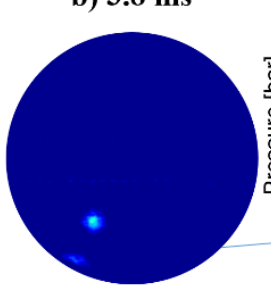

a) $3.6 \mathrm{~ms}$

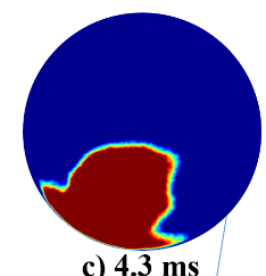

c) $4.3 \mathrm{~ms}$

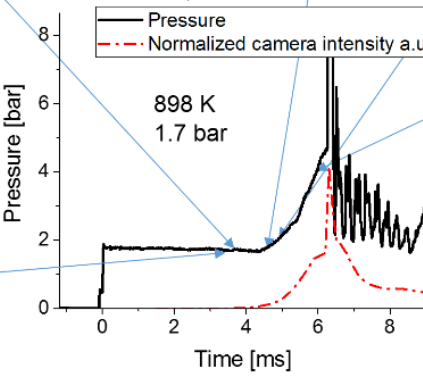

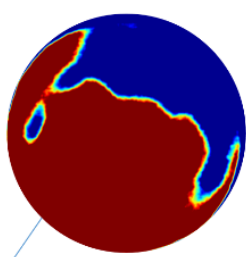

d) $4.9 \mathrm{~ms}$

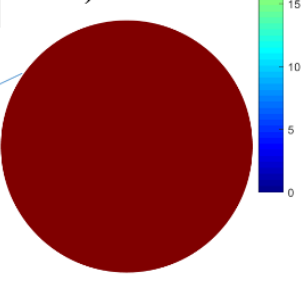

e) $5.9 \mathrm{~ms}$

Fig. 7. $\mathrm{OH}^{*}$ image sequences for $5 \%$ ethanol / 30\% $\mathrm{O}_{2} /$ Ar mixture at $898 \mathrm{~K}$ and 1.7 bar.

In general, at this low-temperature regime $(\sim 850-1000 \mathrm{~K})$, an emission spot confined to a small area can be identified at early stages and the pressure increase is related to the growth of corresponding flame kernel. These ignition cases may be termed 'mild ignition', following the terminology of Oppenheim [36]. Similar observations have recently been made in the shock tube imaging study of Ninnemann et al. [15], where they ascribed 'mild ignition' to high-concentration hydrogen ignition cases at $\mathrm{T}<1000 \mathrm{~K}$.

Figure 8 depicts a condition $(\mathrm{T}=1048 \mathrm{~K})$ which is in the transition from mild to strong ignition regimes. In the early times, a single flame kernel is developed and grows independently, similar to the low-temperature cases. At a later time $(\sim 1.6 \mathrm{~ms})$, a second localized spot appears and propagates parallel to the initial kernel. Thereafter $(\sim 2 \mathrm{~ms})$, a number of agglomerated features appear at the top of the shock tube cross-section. These features combine with the two growing spots to advance to the main ignition. 


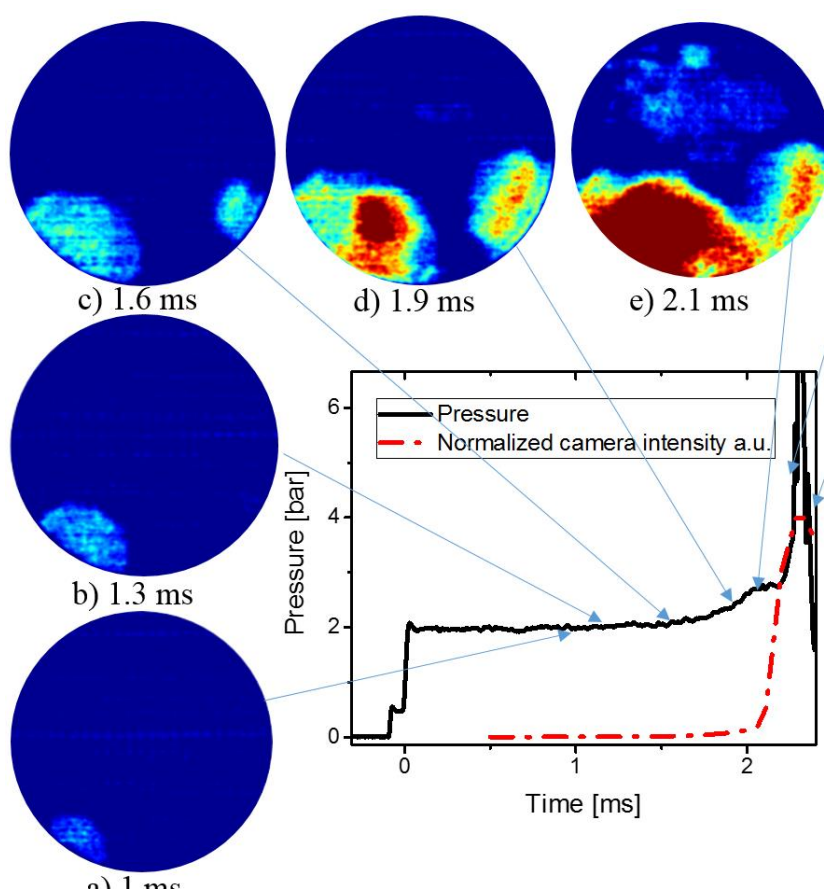

a) $1 \mathrm{~ms}$

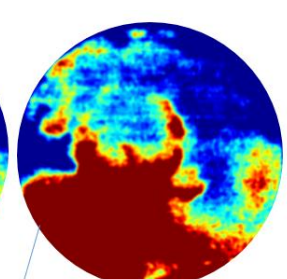

f) $2.2 \mathrm{~ms}$

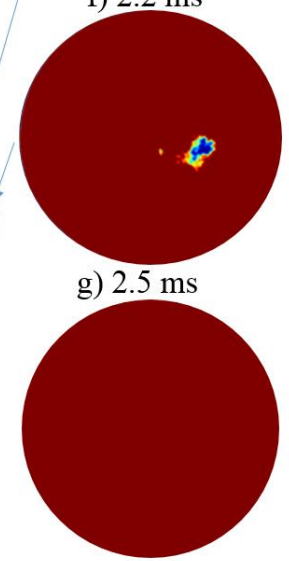

h) $2.7 \mathrm{~ms}$

Fig. 8. $\mathrm{OH}^{*}$ image sequences and pressure trace for 5\% ethanol / 30\% $\mathrm{O}_{2} / \mathrm{Ar}$ mixture at $1048 \mathrm{~K}$ and 2 bar.

Many of the observed features or localized flame kernels are found to initiate very close to the internal wall of the shock tube. This can be promoted by various factors, such as defects on the surface of the test section, port protrusions or window recesses (as discussed by Troutman et al. [14]), combustion product deposits, diaphragm pieces from previous experiments, or interaction of the reflected shock wave with the boundary layer. However, it should be noted that the locations of the initial emission spots were not the same from one experiment to another. For example, emission spots are observed on the right side of the shock tube cross-section in Fig. 9 compared to the lower left side emissions in Figs. 7 and 8. 


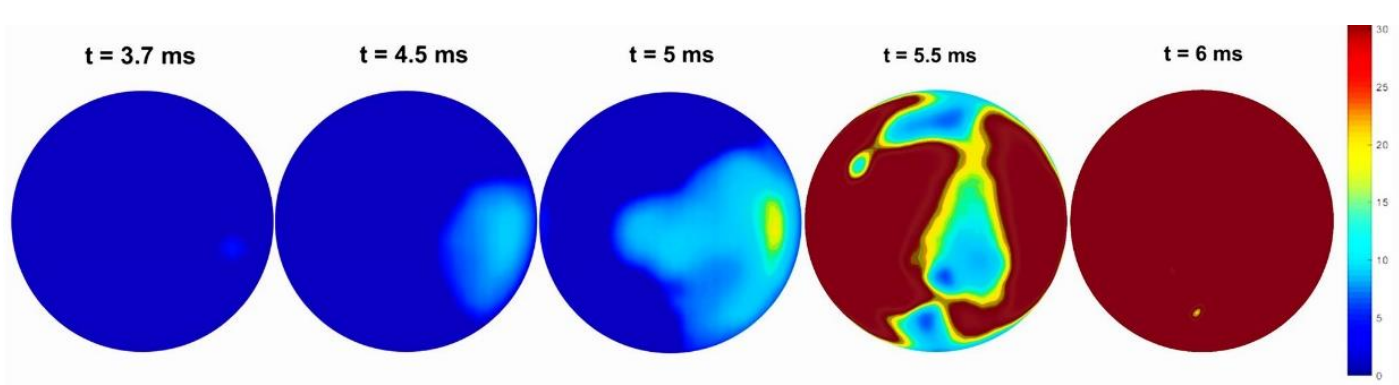

Fig. 9. $\mathrm{OH}^{*}$ image sequences for $5 \%$ ethanol / 30\% $\mathrm{O}_{2} / \mathrm{Ar}$ mixture at $943 \mathrm{~K}$ and 1.9 bar. Here, preignition begins from the right side of the shock tube cross-section.

To minimize user-dependent factors affecting preignition, the shock tube driven section was cleaned thoroughly after every experiment. Few 'dirty' experiments, where the shock tube was not cleaned after a run, showed a clear tendency of ignition initiation from the bottom part of the shock tube cross-section, which can be related to the existence of combustion residuals and/or diaphragm (polycarbonate) pieces settling at the bottom of the shock tube. However, the occurrence of preignition hot spots could not be directly correlated with the cleanliness of the shock tube as these occurrences were highly repeatable at low temperatures and did not correlate with the cleaning / vacuuming procedure.

In order to further analyze the emission fronts that were visualized in the $\mathrm{OH}^{*}$ images, an estimation of the speed of growth of these features was carried out by graphical analysis in Matlab. The captured images were initially thresholded to obtain binary images, and a shape identification code was used afterwards to find the features of interest and determine its area and perimeter, thus estimating its eccentricity. Whenever possible, a characteristic length or radius was estimated using the ratio of the area and perimeter. The speed of growth was then calculated using the rate of change of characteristic length. For a specific low-temperature case at $910 \mathrm{~K}$, the average speed of feature growth was $66 \mathrm{~m} / \mathrm{s}$, whereas the speed was calculated to be $41 \mathrm{~m} / \mathrm{s}$ for a case at $943 \mathrm{~K}$. For high-temperature experiments near $1100-1200 \mathrm{~K}$, rapidness of the process makes it very 
difficult to capture the events on successive frames so these cases are considered as homogeneous ignition.

The calculated speeds are given in Table 2, along with speed of sound and thermal diffusivity of the corresponding mixtures. The front speeds presented here are an average of the front propagation speed observed in subsequent frames. However, these were found to remain almost uniform for the propagation of a specific ignition front (see Fig. 10). Following the terminology of Chen and $\mathrm{Yu}$ [37], the events being observed here are likely related to sequential autoignition because the values of the front speed are maintained in time and that there is not a perceivable abrupt jump in the front velocity.

Table 2. Summary of representative high-speed $\mathrm{OH}^{*}$ imaging experiments

\begin{tabular}{ccccccccccc}
\hline $\begin{array}{c}\mathbf{X}_{\text {Ethanol }} \\
{[\%]}\end{array}$ & $\begin{array}{c}\mathbf{X}_{\mathbf{O} 2} \\
{[\%]}\end{array}$ & $\begin{array}{c}\mathbf{X}_{\mathbf{A r}} \\
{[\mathbf{\%}]}\end{array}$ & $\begin{array}{c}\mathbf{T}_{\mathbf{5}} \\
{[\mathbf{K}]}\end{array}$ & $\begin{array}{c}\mathbf{P}_{\mathbf{5}} \\
{[\mathbf{b a r}]}\end{array}$ & $\begin{array}{c}\mathbf{v}_{\text {exp }} \\
{[\mathbf{m} / \mathbf{s}]}\end{array}$ & $\begin{array}{c}\frac{\boldsymbol{d P}}{\boldsymbol{d} \boldsymbol{t}} \\
{[\boldsymbol{\%} / \mathbf{m s}]}\end{array}$ & $\begin{array}{c}\boldsymbol{\tau}_{\mathbf{i g n}} \\
{[\mathbf{m s}]}\end{array}$ & $\begin{array}{c}\boldsymbol{\alpha}^{*} \mathbf{1 0}^{\mathbf{5}} \\
{\left[\mathbf{m}^{2} / \mathbf{s}\right]}\end{array}$ & $\begin{array}{c}\mathbf{v}_{\text {sound }} \\
{[\mathbf{m} / \mathbf{s}]}\end{array}$ & $\begin{array}{c}\text { Observed } \\
\text { ignition }\end{array}$ \\
\hline 5 & 30 & 65 & 898 & 1.7 & 49 & 1.2 & 6.9 & 7.06 & 477 & Localized \\
5 & 30 & 65 & 910 & 1.7 & 66 & 0.5 & 5.9 & 7.23 & 480 & Localized \\
5 & 30 & 65 & 943 & 1.9 & 41 & 0.6 & 5.3 & 6.86 & 488 & Localized \\
5 & 30 & 65 & 1048 & 2 & $30-47$ & 1.5 & 1.9 & 7.74 & 515 & Intermediate \\
5 & 30 & 65 & 1122 & 2.1 & $\mathrm{H}^{*}$ & 3.8 & 1.3 & 8.27 & 533 & Homogeneous \\
5 & 30 & 65 & 1183 & 2.2 & $\mathrm{H}^{*}$ & 1.9 & 0.95 & 8.64 & 547 & Homogeneous \\
\hline
\end{tabular}

$\mathrm{H}^{*}$ Fast homogeneous ignition
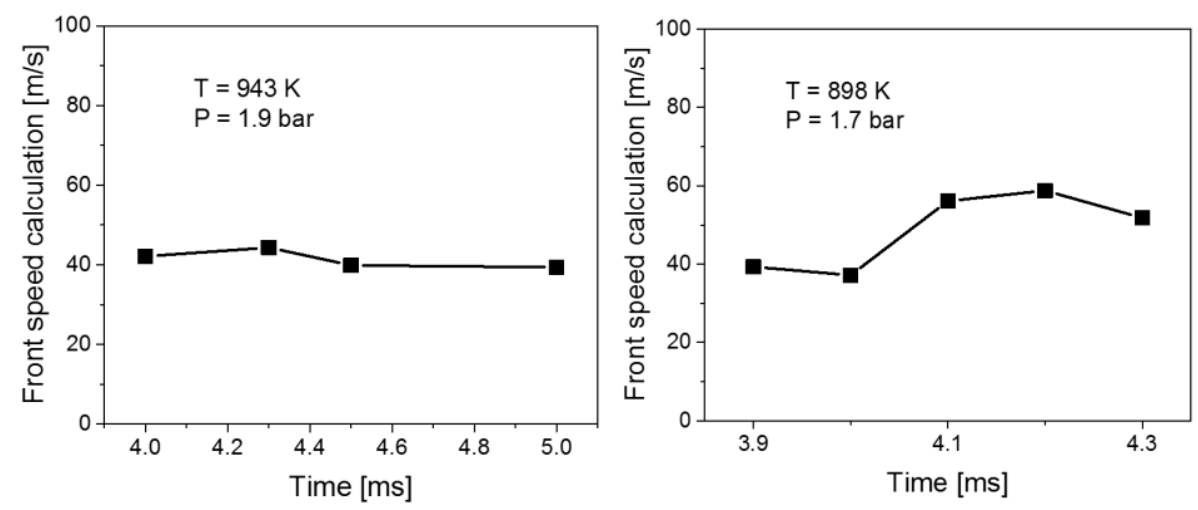

Fig. 10. Calculated front speed as a function of time for two cases exhibiting preignition. Mixture: $5 \%$ ethanol / 30\% $\mathrm{O}_{2} / 65 \%$ Ar. 
Table 2 summarizes relevant information for representative $\mathrm{OH}^{*}$ chemiluminescence imaging experiments. Ignition regimes are observed to be directly related to the temperature range. Localized ignition happens at temperatures less than $1000 \mathrm{~K}$, and there exists an intermediate region where both localized and semi-homogenous processes are observed simultaneously, whereas strong ignition / homogeneous fuel burning is observed for temperatures higher than 1100 K.

\subsection{Thermal Diffusivity and Laminar Flame Thickness}

Walton et al. [16] had argued that mixtures having a higher value of thermal diffusivity would be able to dissipate the temperature gradients in the test section in a faster way, and, therefore, would be less susceptible to inhomogeneous ignition. Our findings are in agreement, as illustrated by the lower thermal diffusivity values for 'localized ignition' cases in Table 2. This argument also explains somewhat larger deviation of our high-pressure data (see Fig. 3); for example, for the 5\% ethanol, $\phi=0.5$ mixture: $\alpha(910 \mathrm{~K}, 1.7 \mathrm{bar})=72.3 \mathrm{~mm}^{2} / \mathrm{s}$ versus $\alpha(910 \mathrm{~K}, 4 \mathrm{bar})=30.7 \mathrm{~mm} / \mathrm{s}^{2}$. This argument points to the notion of a minimum critical value of thermal diffusivity to observe preignition. An increase of pressure of the mixture will result in lower thermal diffusivity, which is why there would be a larger susceptibility to preignition in the 4 bar experiments compared to the 2 bar cases. However, it is important to point out that values of thermal diffusivity may only be used to explain differences observed for a specific mixture. When the reactive mixture is changed, e.g., a different fuel, different concentration of ethanol, relative amount of oxygen, different bath gas, then thermal diffusivity alone cannot be used to related the tendency of the various mixtures to exhibit preignition. 
Kalghatgi and Bradley [28] suggested that the laminar flame thickness of a mixture would dictate its likelihood to pre-ignite. If there exists a hot spot larger than this critical thickness, then this hot spot would be able to develop a flame. That is, a thinner laminar flame thickness would more likely be affected by small temperature inhomogeneities. Laminar flame speed and laminar flame thickness (thermal diffusivity divided by laminar flame speed), as predicted by Metcalfe et al. [34] model, are plotted in Fig. 11 for mixtures containing either Ar or N2 as the bath gas. It is evident that $\mathrm{Ar}$ as a bath gas would promote a thinner flame, thus increasing the susceptibility to promote the development of a kernel. This is in agreement with our results (Fig. 5), where Ar containing mixtures showed more expedited ignition delay times than $\mathrm{N}_{2}$ containing mixtures. Additionally, mixtures with lower concentration of ethanol (2.9\%) would have larger flame thickness and thus less prone to preignition. For the higher concentration of ethanol (5\%) experiments, only lean cases exhibited preignition which can again be correlated to the smaller flame thickness for these mixtures containing larger amounts of oxygen. It is important to note that at higher temperatures, the chemical reactions proceed at a rapid rate and the ignition event is not affected by the differences in flame thickness. There should be then an analogous of a Damköhler number, which relates the ignition delay time to the characteristic time of the flow defined by the ratio of the flame thickness and flame speed [38]. By our observation, whenever $\mathrm{Da}^{*}=\tau_{\text {ign }} / \tau_{\text {char }}>0.015$, preignition can likely affect the ignition process. However, at higher temperatures $\left(\mathrm{Da}^{*}<0.015\right)$, the chemical process is dominant and homogeneous ignition is observed. 

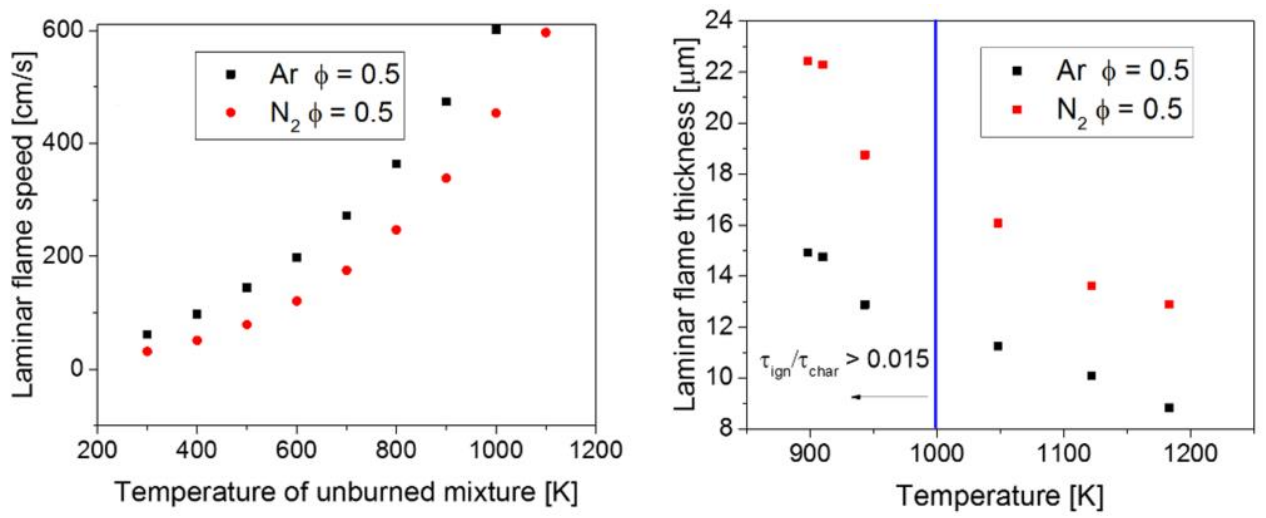

Fig. 11. Predicted laminar flame speed for mixtures containing 5\% ethanol / 30\% $\mathrm{O}_{2} / \mathrm{Ar}, \Phi=0.5$ at 2 bar and calculated laminar flame thickness for the mixture, showing region where preignition affects the measured ignition delay times.

Preignition leading to flame initiation significantly affects ignition delay times in shock tubes, as shown here and in recent studies. The phenomenon seems to be dependent on the fuel and oxidizer concentration and/or properties of the mixture, such as thermal diffusivity and laminar flame thickness. Further experimental and modelling work is needed to better understand these relationships. This is critical not only to understand preignition occurrences in internal combustion engines but also for the shock tube community to ascertain conditions susceptible to inhomogeneous combustion. The current work shows that shock tube pressure time-histories and/or end-wall imaging should be used to ascertain whether measured ignition delays are affected by inhomogenous ignition, and such data should not be used for the development / validation of chemical kinetic models.

\section{Conclusions}

Ignition delay time measurements for $5 \%$ ethanol/ $30 \% \mathrm{O}_{2}$ with $\mathrm{Ar}$ or $\mathrm{N}_{2}$ as bath gas exhibited a clear deviation from the trends predicted by a well-validated chemical kinetic model. Pressure traces showed significant preignition heat release at low temperatures. Two-dimensional $\mathrm{OH}^{*}$ chemiluminescence visualization through the shock tube endwall showed nearly homogeneous 
ignition at high temperatures. Such cases were identified by the formation of various randomly positioned emission spots that merge quickly to consume the fuel almost homogeneously. On the other hand, as the temperatures decreases, a single flame kernel originates and keeps growing until the bulk ignition happens. The preignition processes are most likely events of sequential autoignition as the front speed remains almost uniform. Thermal diffusivity and laminar flame thickness of the mixture are found to have an influence on the likelihood of preignition. Mixtures with lower thermal diffusivity values exhibit localized ignition and expedited ignition delay times. Also, mixtures with a thin flame thickness are more likely to be affected by non-homogeneities. This work highlights the usefulness of imaging experiments in understanding shock tube ignition experiments and points that low-temperature ignition data should be treated with care when used for chemical kinetic model validation.

\section{Acknowledgements}

Research reported in this publication was funded by Saudi Aramco under the FUELCOM program and by King Abdullah University of Science and Technology (KAUST).

\section{References}

[1] T. Javed, J. Badra, M. Jaasim, E. Es-Sebbar, M.F. Labastida, S.H. Chung, H.G. Im, A. Farooq, Shock Tube Ignition Delay Data Affected by Localized Ignition Phenomena, Comb. Sci. Tech. 189 (2017) 1138-1161. 
[2] S.W. Sparrow, PREIGNITION AND SPARK-PLUGS, SAE International, 1920.

[3] A. HUNDERE, J.A. BERT, PREIGNITION And Its Deleterious Effects in Aircraft Engines, SAE International, 1948.

[4] L.L. Withrow, F.W. Bowditch, Flame Photographs of Autoignition Induced by CombustionChamber Deposits, SAE International, 1952.

[5] E.M. Chapman, V.S. Costanzo, A Literature Review of Abnormal Ignition by Fuel and Lubricant Derivatives, SAE Int. J. Engines 9 (2015) 107-142.

[6] C. Dahnz, K.-M. Han, U. Spicher, M. Magar, R. Schiessl, U. Maas, Investigations on PreIgnition in Highly Supercharged SI Engines, SAE Int. J. Engines 3 (2010) 214-224.

[7] B.M. Sturgis, Abnormal Combustion Problems in Gasoline Engines, SAE International, 1961.

[8] A.E. Felt, J.A. Warren, C.A. Hall, RUMBLE — a deposit effect at high compression ratios, SAE International, 1959.

[9] A. Zahdeh, P. Rothenberger, W. Nguyen, M. Anbarasu, S. Schmuck-Soldan, J. Schaefer, T. Goebel, Fundamental Approach to Investigate Pre-Ignition in Boosted SI Engines, SAE Int. J. Engines 4 (2011) 246-273.

[10] L.F. Dumont, Possible Mechanisms by which Combustion-Chamber Deposits Accumulate and Influence Knock, SAE International, 1951.

[11] G.T. Kalghatgi, D. Bradley, Pre-ignition and 'super-knock' in turbo-charged spark-ignition engines, Int. J. Engine Res. 13 (2012) 399-414.

[12] D.F. Davidson, R.K. Hanson, Interpreting shock tube ignition data, Int. J. Chem. Kinet. 36 (2004) 510-523.

[13] Y. Uygun, S. Ishihara, H. Olivier, A high pressure ignition delay time study of 2-methylfuran and tetrahydrofuran in shock tubes, Combust. Flame 161 (2014) 2519-2530. 
[14] V.A. Troutman, C.L. Strand, M.F. Campbell, A.M. Tulgestke, V.A. Miller, D.F. Davidson, R.K. Hanson, High-speed $\mathrm{OH}^{*}$ chemiluminescence imaging of ignition through a shock tube end-wall, Appl. Phys. B 122 (2016) 56.

[15] E. Ninnemann, B. Koroglu, O. Pryor, S. Barak, L. Nash, Z. Loparo, J. Sosa, K. Ahmed, S. Vasu, New insights into the shock tube ignition of $\mathrm{H} 2 / \mathrm{O} 2$ at low to moderate temperatures using high-speed end-wall imaging, Combust. Flame 187 (2018) 11-21.

[16] S.M. Walton, X. He, B.T. Zigler, M.S. Wooldridge, A. Atreya, An experimental investigation of iso-octane ignition phenomena, Combust. Flame 150 (2007) 246-262.

[17] Z. Wang, Y. Qi, X. He, J. Wang, S. Shuai, C.K. Law, Analysis of pre-ignition to super-knock: Hotspot-induced deflagration to detonation, Fuel 144 (2015) 222-227.

[18] M.R. Herfatmanesh, P. Lu, M.A. Attar, H. Zhao, Experimental investigation into the effects of two-stage injection on fuel injection quantity, combustion and emissions in a high-speed optical common rail diesel engine, Fuel 109 (2013) 137-147.

[19] A. Khalid, B. Manshoor, Analysis of mixture formation and flame development of diesel combustion using a rapid compression machine and optical visualization technique, Appl. Mech. Mater., 315, (2013) 293-298

[20] Y. Xiong, W.L. Roberts, M.C. Drake, T.D. Fansler, Investigation of pre-mixed flamekernel/vortex interactions via high-speed imaging, Combust. Flame 126 (2001) 1827-1844.

[21] L.M. Pickett, S. Kook, T.C. Williams, Visualization of Diesel Spray Penetration, Cool-Flame, Ignition, High-Temperature Combustion, and Soot Formation Using High-Speed Imaging, SAE Int. J. Engines 2 (2009) 439-459. 
[22] H. Persson, A. Hultqvist, B. Johansson, A. Remón, Investigation of the Early Flame Development in Spark Assisted HCCI Combustion Using High Speed Chemiluminescence Imaging, SAE International, 2007.

[23] J. Herzler, L. Jerig, P. Roth, Shock tube study of the ignition of lean n-heptane/air mixtures at intermediate temperatures and high pressures, Proc. Combust. Inst. 30 (2005) 1147-1153.

[24] O. Pryor, S. Barak, E. Ninnemann, S. Vasu. Dynamics of Ignition observed through High Speed Imaging inside a shock tube. In: editor^editors. 2017. p. 4772.

[25] O. Pryor, S. Barak, B. Koroglu, E. Ninnemann, S.S. Vasu, Measurements and interpretation of shock tube ignition delay times in highly $\mathrm{CO} 2$ diluted mixtures using multiple diagnostics, Combust. Flame 180 (2017) 63-76.

[26] S. Barak, O. Pryor, J. Lopez, E. Ninnemann, S. Vasu, B. Koroglu, High-Speed Imaging and Measurements of Ignition Delay Times in Oxy-Syngas Mixtures With High CO2 Dilution in a Shock Tube, J. Eng. Gas Turb. Power 139 (2017) 121503-121503-121507.

[27] K. Fieweger, R. Blumenthal, G. Adomeit, Self-ignition of S.I. engine model fuels: A shock tube investigation at high pressure, Combust. Flame 109 (1997) 599-619.

[28] G.T. Kalghatgi, D. Bradley, Pre-ignition and 'super-knock' in turbo-charged spark-ignition engines, Int. J. Engine Res. 13 (2012) 399-414.

[29] C. Lee, S. Vranckx, A. Heufer Karl, V. Khomik Sergey, Y. Uygun, H. Olivier, X. Fernandez Ravi, On the Chemical Kinetics of Ethanol Oxidation: Shock Tube, Rapid Compression Machine and Detailed Modeling Study, Zeitschrift für Physikalische Chemie, 2012, pp. 1.

[30] M. Sarathy, P. Oßwald, N. Hansen, K. Kohse-Höinghaus, Alcohol combustion chemistry, Prog. Energy Combust. Sci. 
[31] Z. Hong, G.A. Pang, S.S. Vasu, D.F. Davidson, R.K. Hanson, The use of driver inserts to reduce non-ideal pressure variations behind reflected shock waves, Shock Waves 19 (2009) $113-123$.

[32] J. Badra, A.E. Elwardany, F. Khaled, S.S. Vasu, A. Farooq, A shock tube and laser absorption study of ignition delay times and $\mathrm{OH}$ reaction rates of ketones: 2-Butanone and 3-buten-2one, Combust. Flame 161 (2014) 725-734.

[33] K.E. Noorani, B. Akih-Kumgeh, J.M. Bergthorson, Comparative high temperature shock tube ignition of C1-C4 primary alcohols, Energy Fuels 24 (2010) 5834-5843.

[34] W.K. Metcalfe, S.M. Burke, S.S. Ahmed, H.J. Curran, A hierarchical and comparative kinetic modeling study of C1- C2 hydrocarbon and oxygenated fuels, Int. J. Chem. Kinet. 45 (2013) 638-675.

[35] K.P. Grogan, M. Ihme, Weak and strong ignition of hydrogen/oxygen mixtures in shock-tube systems, Proc. Combust. Inst. 35 (2015) 2181-2189.

J.W. Meyer, A.K. Oppenheim. On the shock-induced ignition of explosive gases. 1971: Elsevier. p. $1153-1164$.

[37] H. Yu, Z. Chen, End-gas autoignition and detonation development in a closed chamber, Combust. Flame 162 (2015) 4102-4111.

[38] H.G. Im, P. Pal, M.S. Wooldridge, A.B. Mansfield, A Regime Diagram for Autoignition of Homogeneous Reactant Mixtures with Turbulent Velocity and Temperature Fluctuations, Comb. Sci. Tech. 187 (2015) 1263-1275 
[39] E.L. Petersen, D.M. Kalitan, A.B. Barrett, S.C. Reehal, J.D. Mertens, D.J. Beerer, R.L. Hack, V.G. McDonell, New syngas/air ignition data at lower temperature and elevated pressure and comparison to current kinetics models, Combust. Flame 149 (2007) 244-247. 